\title{
Utilization of Sodium Chloride Solutions to Obtain Ferrous Chlorides
}

\author{
Mykola Gomelya', Yana Kryzhanovska', Tetyana Shabliy ${ }^{1 *}$, Olena Levytska ${ }^{2}$ \\ 1 Department of Ecology and Technology of Plant Polymers, Faculty of Chemical Engineering, Igor Sikorsky \\ Kyiv Polytechnic Institute, Peremogy Avenu 37/4, 03056 Kyiv, Ukraine \\ 2 Department of Life Safety, Physical and Technical Faculty, Oles Honchar Dnipro National University, Gagarin \\ avenue 72, 49010 Dnipro city, Ukraine \\ * Corresponding author's e-mail: dsts1@ukr.net
}

\begin{abstract}
In this work, the processes of electrochemical processing of sodium chloride solutions with the production of iron (III) chloride and alkali in a three-chamber electrolyzer with MA-41 anion-exchange membrane and MK-40 cation-exchange membrane were investigated. The conditions for the removal of sodium chloride from water in a three-chamber electrolyzer using an iron anode were determined depending on the anode current density and the reaction of the medium in the anode region. The parameters of the process of concentrating iron chloride in the anode region were established at relatively low concentrations of sodium chloride solution. It was shown that during the electrolysis of a sodium chloride solution with a concentration of $370 \mathrm{mg}$-eq/ $\mathrm{dm}^{3}$ at a current of $0.2 \mathrm{~A}$ in a three-chamber electrolyzer with an iron anode, an iron chloride solution is formed in the anolyte at $\mathrm{pH}<4.9$. The rate of concentration of $\mathrm{NaOH}$ to catholyte and $\mathrm{FeCl}^{3}$ to anolyte increased along with the current density. It was found that in order to increase the concentration of iron (III) chloride in the anolyte at relatively low concentrations of sodium chloride solution, it is advisable to gradually renew the demineralized solutions in the working chamber.
\end{abstract}

Keywords: sodium chloride, ferric chloride, electrolysis, catholyte, anolyte, three-chamber electrolyzer

\section{INTRODUCTION}

The problem of desalination of natural, mine waters and waters with increased mineralization is quite acute today. Actually, the processes of desalination of waters of different mineralization are well studied. Different methods are used depending on the concentration of salts in the water. For the waters with salinity from $1000 \mathrm{mg} / \mathrm{dm}^{3}$ to 20-30 thousand $\mathrm{mg} / \mathrm{dm}^{3}$, ion exchange [Gomelya et al., 2016; Makarenko et al., 2013], membrane methods, including baromembrane processes [Naidu et al., 2015; Epsztein et al., 2015] and electrodialysis [Gomelya et al., 2018; Gomelya et al., 2019] are used. Freezing of water is less common [Htira et al., 2018].

When processing more concentrated solutions, evaporators [Lin Chen et al., 2020; Ferry et al., 2020] and dryers [Wenyi Deng et al., 2013] are used. However, all these known methods, even with complex use, do not solve the problem of water desalination without the formation and accumulation of concentrates. The discharge of concentrates without processing does not solve, but exacerbates the problem [Shabliy et al., 2010].

The disadvantage of ion exchange is the use of aggressive and expensive acids and alkalis in the regeneration of ion exchangers [Gomelya et al., 2016; Makarenko et al., 2013]. In this case, the total amount of salts in the spent eluate at times exceeds the amount of salts that was in demineralized water. The reverse osmosis processes are devoid of this disadvantage. However, they are effective only in a certain range of salt concentrations [Goncharuk et al., 2013] and are accompanied by the formation of concentrates, the salt content of which reaches $5-15 \%$. In addition, the use of reverse osmosis involves the use of preliminary water purification from suspended and colloidal impurities [Trus et al., 2013]. The same applies to electrodialysis [Akhter et al., 2018]. Evaporation [Shata et al., 2014] and freezing 
[Adeniyi et al., 2014] of water are less dependent on the concentration of impurities. However, they are characterized by high energy consumption, especially the processes of water evaporation and drying of the obtained crystalline residues [Bennamoun et al., 2013]. In addition, these processes do not solve the problem related to the utilization of the separated mineral salts. It is difficult to use them, because they occur mainly in the form of mixtures, and can only be disposed of in special storage facilities, the construction and operation of which is unreasonably expensive.

The most expedient are the approaches aimed at processing the obtained concentrate of salts to obtain useful products. If sulfates, calcium and magnesium compounds can be relatively easily isolated from water, then the processing of sodium chloride solutions is the most problematic.

The aim of this work was to determine the conditions for the electrochemical processing of sodium chloride solutions to obtain concentrated solutions of iron (III) chloride and alkali.

In order to achieve the set goal, it is necessary to solve the following scientific problems:

1. Determine the conditions for removing sodium chloride from water in a three-chamber electrolyzer using an iron anode, depending on the anode current density, the reaction of the medium in the anode region.

2. Establish the parameters of the process of concentrating iron chloride in the anode region at relatively low concentrations of sodium chloride solution.

\section{MATERIALS AND METHODS}

In the work, three-chamber electrolysis installations were used, in which MK-40 cationexchange membrane and MA-41 anion-exchange membrane were used. The volume of the cathode, working, and anode chambers was 75 or $100 \mathrm{~cm}^{3}$. The cathode area is equal to the anode area and is equal to $0.12 \mathrm{dm}^{3}$. The cathode is the $12 \mathrm{X} 18 \mathrm{H} 10 \mathrm{~T}$ alloy steel, the anode is the St3 steel. A direct current source was used for electrolysis. In the cathode chamber, weakly alkaline solutions were used $\left(\mathrm{L}=50-70 \mathrm{mg}\right.$-eq $\left./ \mathrm{dm}^{3}\right)$. In the anode chamber, weakly acidic hydrochloric acid solutions of $0.5-50 \mathrm{mg}-\mathrm{eq} / \mathrm{dm}^{3}$ were used. The working chamber contained sodium chloride solutions with a concentration of $370 \mathrm{mg}-\mathrm{eq} / \mathrm{dm}^{3}$.
The selected concentration of the working solution is due to the following. The chloride concentration of $370 \mathrm{mg}-\mathrm{eq} / \mathrm{dm}^{3}$ corresponds to a weight concentration of chlorides of $13.135 \mathrm{~g} / \mathrm{dm}^{3}$ or a sodium chloride concentration of $21.645 \mathrm{~g} / \mathrm{dm}^{3}$. As a rule, the concentration of salts in the concentrates of reverse osmosis water desalination is in the range of $2-6 \%$. A further increase in the concentration of salts in the concentrate is accompanied by a significant increase in the osmotic pressure of the concentrate, which necessitates the use of systems with a high working pressure. This leads to higher equipment and energy costs. In addition, the selectivity of the process is sharply reduced.

The electrolysis was carried out at a current of $0.2 \mathrm{~A}$, measuring the alkalinity in the cathode and working chambers, the concentration of chlorides in the working and anode chambers, the concentration of iron and the $\mathrm{pH}$ of the medium in the anode chamber.

The current yield of the substance $(B, \%)$ was calculated by means of the formula:

$$
B=\frac{m_{p}}{m_{t}} \cdot 100, \%,
$$

where: $m_{p}$ - the mass of the substance obtained (dissolved, transferred to another chamber) actually in the electrolysis process, g; $m_{t}$ - the mass of the substance obtained (dissolved, transferred to another chamber) calculated theoretically, $g$

$$
m_{t}=K_{F} \cdot I \cdot t
$$

where: $K_{F}=0.0371 \mathrm{~mol} /(\mathrm{A} \cdot \mathrm{h})$;

$I$ - current strength, A; $t$ - time, $\mathrm{h}$.

$$
m_{p}=V_{s} \cdot\left(C_{0}-C\right)
$$

where: $V_{S}$ - the volume of the treated solution, $\mathrm{dm}^{3}$

$C_{0}-$ initial component concentration, $\mathrm{mol} / \mathrm{dm}^{3}$,

C - final component concentration after treatment, $\mathrm{mol} / \mathrm{dm}^{3}$.

The extraction degree of chlorides (sodium chloride) from the working chamber (Z, \%) was calculated by the formula:

$$
Z=\left(1-\frac{C}{C_{0}}\right) \cdot 100, \%
$$

where: $C$ - the final concentration of the component after treatment, $\mathrm{mol} / \mathrm{dm}^{3}$; $C_{0}$ - initial concentration of the component, $\mathrm{mol} / \mathrm{dm}^{3}$. 


\section{RESULTS AND DISCUSSION}

The process of obtaining iron chloride by electrolysis is superior to other methods of electrochemical processing of sodium chloride wastes in terms of simplicity. In this case, cheap anodes made of steel 3 or other iron materials are used (unlike chlorine oxidation processes, where it is necessary to use oxidation-resistant plate anodes, titanium coated with ruthenium oxide, and resistant organic electrodes [Gomelya et al., 2018; Gomelya et al., 2019]). However, the implementation of the process of obtaining iron (III) chloride in a three-chamber electrolytic cell is not as easy as one might expect.

In general, the implementation of the following process scheme was envisaged. Sodium chloride was in the middle working chamber, separated from the cathode area by MK-40 cation-exchange membrane and from the anode chamber by MA-41 anion-exchange membrane. At a voltage of 5-50 V, sodium ions diffuse through the cation-exchange membrane into the cathode region, whereas the hydrogen and hydroxide anions are formed at the cathode following the reactions:

$$
\begin{gathered}
2 \mathrm{H}^{+}+2 \mathrm{e} \rightarrow \mathrm{H}_{2} \uparrow \\
2 \mathrm{H}_{2} \mathrm{O}+2 \mathrm{e} \rightarrow \mathrm{H}_{2} \uparrow+2 \mathrm{OH}^{-}
\end{gathered}
$$

In the presence of sodium cations in the cathode chamber, alkali is concentrated. The chlorides from the working chamber diffuse into the anode chamber, where anodic dissolution of iron occurs:

$$
\mathrm{Fe}-2 \mathrm{e}=\mathrm{Fe}^{2+}
$$

As a rule, during the anodic dissolution of iron, $\mathrm{Fe}^{2+}$ cations are formed. This is confirmed by numerous publications on the use of electrocoagulation using iron electrodes [Bazrafshan et al., 2012; Chafi et al., 2011].

However, with an increase in the concentration of chlorides in the anode chamber at $\mathrm{pH}>6$, the formation of oxygen and/or active chlorine is possible:

$$
\begin{gathered}
2 \mathrm{H}_{2} \mathrm{O}-4 \mathrm{e}=\mathrm{O}_{2}+4 \mathrm{H}^{+} \\
2 \mathrm{Cl}^{-}-2 \mathrm{e}=\mathrm{Cl}_{2} \uparrow
\end{gathered}
$$

Iron (III) chloride can be formed by the interaction of iron dichloride with molecular chlorine:

$$
2 \mathrm{FeCl}_{2}+\mathrm{Cl}_{2}=2 \mathrm{FeCl}_{3}
$$

When iron (II) ions interact with oxygen in the presence of chlorides, the formation of iron oxychloride is possible:

$$
\begin{gathered}
2 \mathrm{FeCl}_{2}+\mathrm{O}_{2}+2 \mathrm{H}^{+}=2 \mathrm{FeOCl}+2 \mathrm{HCl} \\
2 \mathrm{FeCl}_{2}+\mathrm{O}_{2}+\underset{2 \mathrm{H}_{2} \mathrm{O}=2 \mathrm{Fe}(\mathrm{OH}) \mathrm{Cl}_{2}}{2 \mathrm{H}^{-}}
\end{gathered}
$$

Iron oxychlorides can also be formed during the hydrolysis of iron (II) and iron (III):

$$
\begin{gathered}
\mathrm{Fe}^{2+}+\mathrm{H}_{2} \mathrm{O}=\mathrm{Fe}(\mathrm{OH})^{+}+\mathrm{H}^{+} \\
\mathrm{Fe}(\mathrm{OH})^{+}+\mathrm{H}_{2} \mathrm{O}=\mathrm{Fe}(\mathrm{OH})_{2}+\mathrm{H}^{+} \\
\mathrm{Fe}^{3+}+\mathrm{H}_{2} \mathrm{O}=\mathrm{Fe}(\mathrm{OH})^{2+}+\mathrm{H}^{+} \\
\mathrm{Fe}(\mathrm{OH})^{2+}+\mathrm{H}_{2} \mathrm{O}=\mathrm{Fe}(\mathrm{OH})_{2}^{+}+\mathrm{H}^{+} \\
\mathrm{Fe}(\mathrm{OH})_{2}^{+}+\mathrm{H}_{2} \mathrm{O}=\mathrm{Fe}(\mathrm{OH})_{3}+\mathrm{H}^{+}
\end{gathered}
$$

If Figure 1 is considered, then a certain misunderstanding of the presented results arises.

After 7 hours of electrolysis of sodium chloride solution in a three-chamber electrolyzer, an increase in alkalinity in the cathode region by $241 \mathrm{mg}$-eq $/ \mathrm{dm}^{3}$, a decrease in the concentration of chlorides in the working chamber by $312 \mathrm{mg}-\mathrm{eq} / \mathrm{dm}^{3}$, and an increase in the concentration of iron in the anolyte to only $90.9 \mathrm{mg}$-eq/ $\mathrm{dm}^{3}$ were noted. In this case, the current efficiency of alkali reached $24-61 \%$ with an average value of $34.6 \%$, the current efficiency of oxidized iron reached $5.1-38.5 \%$ with an average value of $14.49 \%$, and the current efficiency transferred from the working chamber to the anodic region of chlorides is $17-81 \%$ with an average value of $46.4 \%$ (Fig. 2). The degree of purification of the sodium chloride solution from chlorides reached $84.5 \%$.

First of all, doubts arise as a result of the amount of chlorides transferred to the anodic region, which reaches $312 \mathrm{mg}-\mathrm{eq} / \mathrm{dm}^{3}$ and an insignificant concentration of dissolved iron $\left(90.9 \mathrm{mg}-\mathrm{eq} / \mathrm{dm}^{3}\right)$. If it is assumed that little iron has dissolved, then the acidity of the anolyte should be expected at the level of $200 \mathrm{mg}-\mathrm{eq} / \mathrm{dm}^{3}$.

However, judging by the change in the $\mathrm{pH}$ of the medium in the anolyte (Fig. 3), it is possible to say that the $\mathrm{pH}$ of the solution increased from 4.78 to 5.4. Obviously, in this case, quite a lot of iron passed into solution during anodic dissolution. However, it is quite possible that a significant part of it, together with chlorides, precipitated in the form of oxychlorides: 


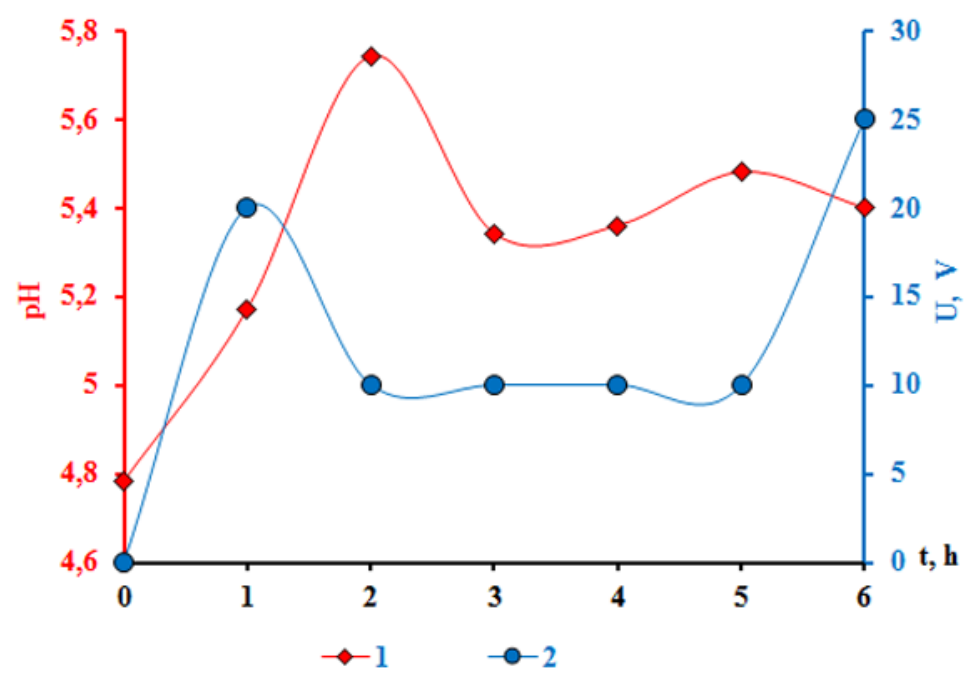

Fig. 3. Dependence of the $\mathrm{pH}$ of the medium (1) in the anode region and voltage (2) on the time of electrolysis of sodium chloride solution $\left([\mathrm{NaCl}]=370 \mathrm{mg}\right.$-eq $\left./ \mathrm{dm}^{3}\right)$ in a three-chamber electrolyzer $\left(\mathrm{V}_{\mathrm{k}}=75 \mathrm{~cm}^{3}\right.$, $\mathrm{I}=0.2 \mathrm{~A}, \mathrm{j}=1.67 \mathrm{~A} / \mathrm{dm}^{3}$ ) with iron anode

$0.5 \mathrm{mg}$-eq $/ \mathrm{dm}^{3}$ was added to the anode chamber for sufficient electrical conductivity, then in the next experiment, $1.5 \mathrm{mg}$-eq $/ \mathrm{dm}^{3} \mathrm{HCl}$ was added to the anode chamber. The electrolysis results are shown in Fig. 4-6.

As can be seen from Fig. 4, in this case, simultaneously with a significant decrease in the concentration of chlorides in the working chamber, a significant increase in iron ions into anolyte was observed. Alkalinity in the cathode region grew somewhat more slowly.

As already mentioned, the resistance to diffusion of sodium ions into the cathode region increases along with the alkalinity of the catholyte, but with an increase in the concentration of iron in the anode region, the resistance to diffusion of chlorides into this region decreases.

Therefore, the diffusion of chlorides into the anodic region is better than the diffusion of sodium into the cathode region. This leads to an increase in alkalinity in the working chamber up to $19-22 \mathrm{mg}-\mathrm{eq} / \mathrm{dm}^{3}$ and causes an increase in the current efficiency during diffusion of chlorides, compared to the current efficiency of alkali in catholyte (Fig. 5).

The unexpected increase in the concentration of iron in the anolyte can be explained by a decrease in the $\mathrm{pH}$ of the medium, which

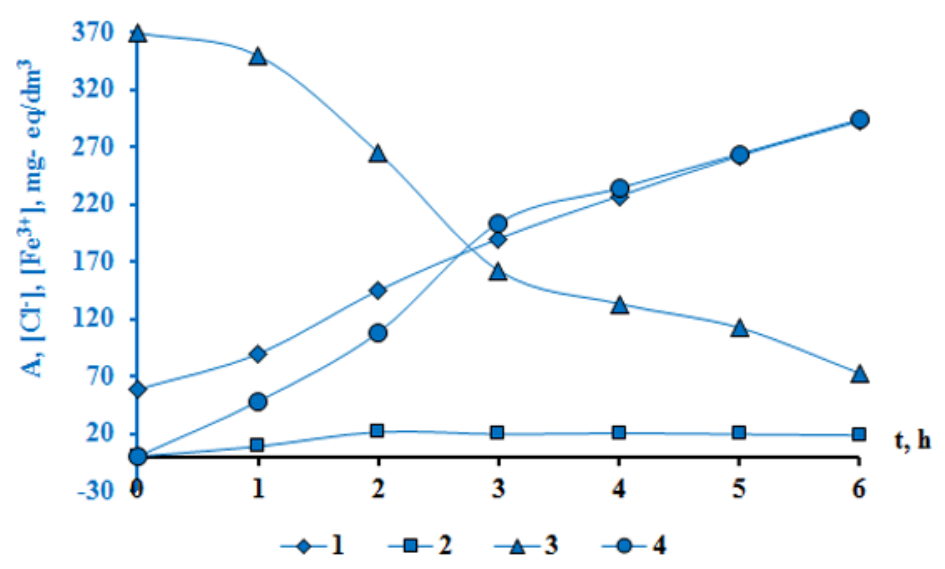

Fig. 4. Dependence of alkalinity in the cathode region (1), working chamber (2), chloride concentration in the working chamber (3), iron concentration (4) on the electrolysis time of sodium chloride solution $\left([\mathrm{NaCl}]=370 \mathrm{mg}\right.$-eq $\left./ \mathrm{dm}^{3}\right)$ in three-chamber electrolyzer $\left(\mathrm{V}_{\mathrm{k}}=75 \mathrm{~cm}^{3}, \mathrm{f}_{\mathrm{k}}=\mathrm{f}_{\mathrm{a}}=12 \mathrm{~cm}^{3}, \mathrm{I}=0.2 \mathrm{~A}, \mathrm{j}=1.67 \mathrm{~A} / \mathrm{dm}^{3}\right)$ with an iron anode 


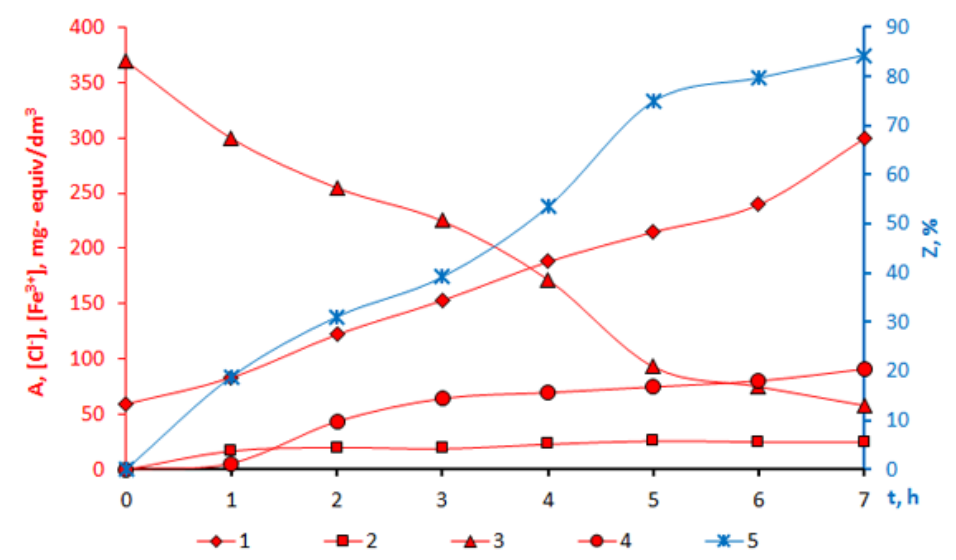

Fig. 1 Change in alkalinity in the cathode region (1), in the working chamber (2), the concentration of chlorides in the working chamber (3), the concentration of iron in the anode region (4) and the degree of extraction of chlorides (5) versus the time of electrolysis of sodium chloride solution $\left([\mathrm{NaCl}]=370 \mathrm{mg}-\mathrm{eq} / \mathrm{dm}^{3}\right)$ in a threechamber electrolyzer $\left(V_{k}=75 \mathrm{~cm}^{3}, I=0.2 \mathrm{~A}, \mathrm{j}=1.67 \mathrm{~A} / \mathrm{dm}^{3}\right)$ using an iron anode

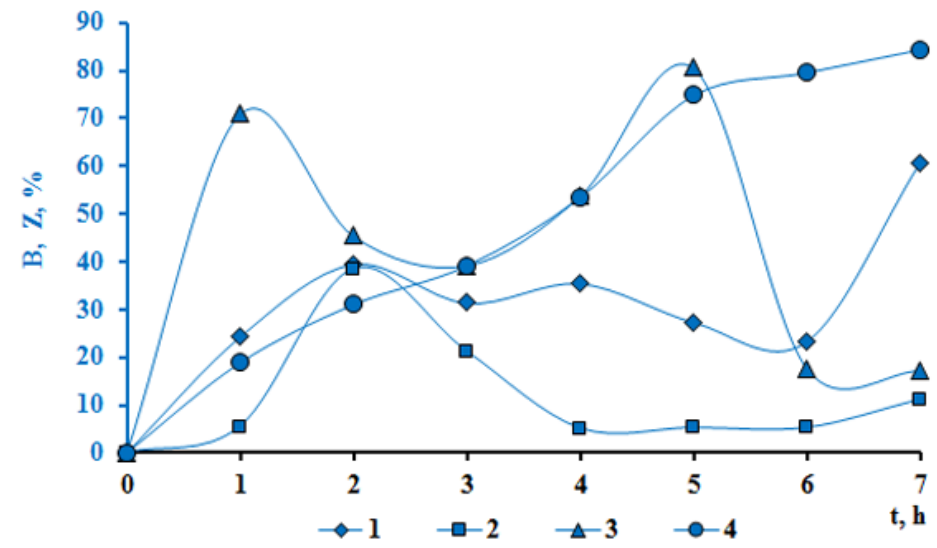

Fig. 2. Dependence of the current efficiency of alkali in the cathode region (1), oxidized iron $\left(\mathrm{Fe}^{3+}\right)$ in the anode region (2), diffusion of chlorides from the working chamber into the anode region (3) and the degree of extraction of chlorides (4) during electrolysis of sodium chloride solution $([\mathrm{NaCl}]=370 \mathrm{mg}$-eq/dm $)$ in a threechamber electrolyzer $\left(V_{k}=75 \mathrm{~cm}^{3}, I=0.2 \mathrm{~A}, j=1.67 \mathrm{~A} / \mathrm{dm}^{3}\right)$

$$
\begin{gathered}
\mathrm{FeCl}_{3}+\mathrm{H}_{2} \mathrm{O}=\mathrm{Fe}(\mathrm{OH}) \mathrm{Cl}_{2} \downarrow+\mathrm{HCl} \\
\mathrm{FeCl}_{3}+\mathrm{H}_{2} \mathrm{O}=\mathrm{FeOCl}_{2} \downarrow+\mathrm{HCl}
\end{gathered}
$$

Reactions (14), (15) are essentially analytical reactions (11) and (12). The formation of $\mathrm{Fe}(\mathrm{OH})$ $\mathrm{Cl}_{2}$ and $\mathrm{FeOCl}$ is also possible after reactions 7 and 8 . Formed hydrochloric acid can bind when interacting with the iron anode by the reaction:

$$
\mathrm{Fe}+2 \mathrm{HCl}=\mathrm{FeCl}_{2}+\mathrm{H}_{2} \uparrow
$$

Probably, it is the efficient binding of chlorides into salts and iron oxychlorides that explains their better diffusion into the anodic region, in comparison with the diffusion of sodium into the cathodic region (Fig. 1). That is why, the current efficiency when removing the chlorides from the anode region is higher than the alkali current efficiency in the cathode region. This can explain the increase in alkalinity in the working chamber up to $26 \mathrm{mg}$-eq $/ \mathrm{dm}^{3}$ and high values of the degree of purification of the working solution of chlorides (Fig. 3). In addition, it is possible to remove chlorine $\left(\mathrm{Cl}_{2}\right)$ formed by reaction (5) by degassing.

However, the low values of the concentration of iron ions in the anolyte can be explained by the fact that at $\mathrm{pH} 5.17-5.74$ most of it is in a bound insoluble state.

An increase in voltage at the end of the electrolysis process at $\mathrm{I}=0.2 \mathrm{~A}$ from $10 \mathrm{~V}$ to $25 \mathrm{~V}$ is due to a drop in the concentration of sodium chloride in the working chamber.

If in previous experiments, a solution of hydrogen chloride with a concentration of 


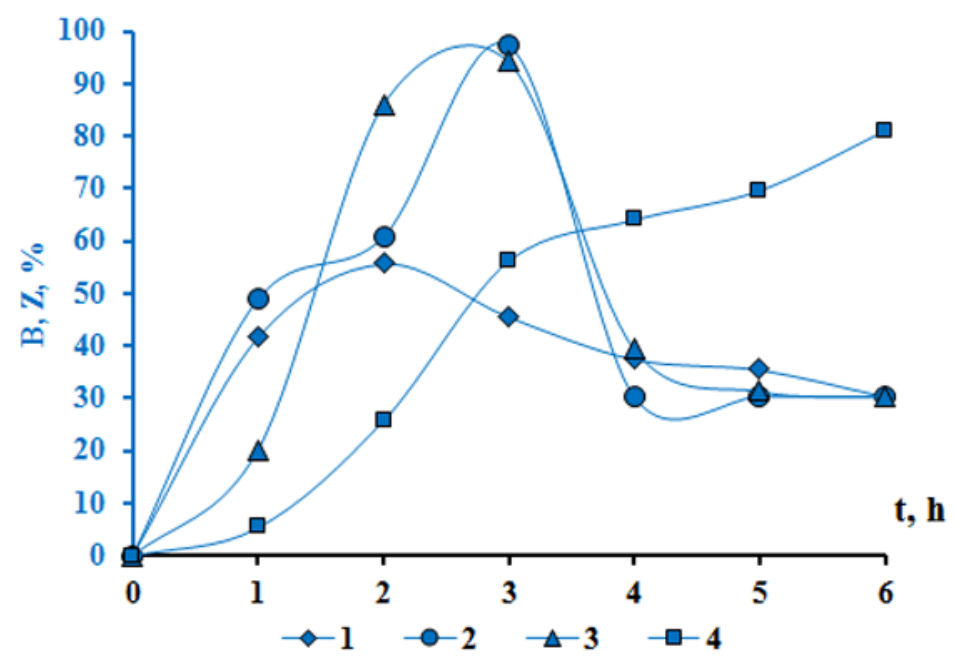

Fig. 5. Change in the current efficiency of alkali in the cathode region (1), iron in the anodic region (2), diffusion of chlorides from the anodic region into the working region (3), the degree of extraction of chlorides (4) during electrolysis of sodium chloride solution $\left([\mathrm{NaCl}]=370 \mathrm{mg}\right.$-eq/dm $\left.\mathrm{dm}^{3}\right)$ in a three-chamber electrolyzer $\left(\mathrm{V}_{\mathrm{k}}=75 \mathrm{~cm}^{3}\right.$, $\left.\mathrm{I}=0.2 \mathrm{~A}, \mathrm{j}=1.67 \mathrm{~A} / \mathrm{dm}^{3}\right)$

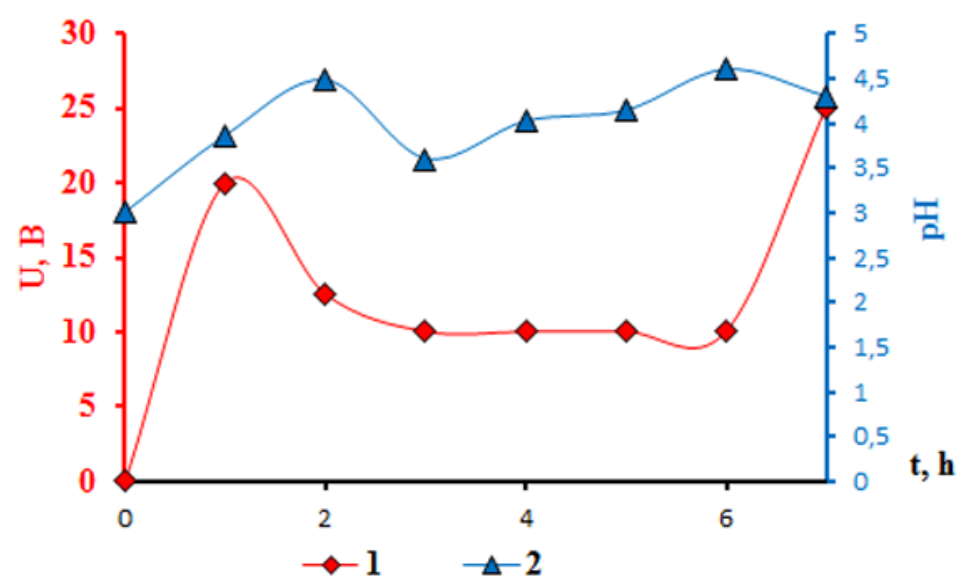

Fig. 6. Change in voltage (1) and $\mathrm{pH}(2)$ of the medium in the anode region with the time of electrolysis of a NaCl solution $\left([\mathrm{NaCl}]=370 \mathrm{mg}\right.$-eq $\left./ \mathrm{dm}^{3}\right)$ in a three-chamber electrolyzer $\left(\mathrm{V}_{\mathrm{k}}=75 \mathrm{~cm}^{3}, \mathrm{I}=0.2 \mathrm{~A}, \mathrm{j}=1\right.$, $\left.67 \mathrm{~A} / \mathrm{dm}^{3}\right)$

ensures the existence of iron in the form of $\mathrm{FeCl}_{3}$, which is highly soluble in water. At the same time, the $\mathrm{pH}$ of the medium varied within 3.0-4.6 (Fig. 6).

The voltage at the beginning of the process was at the level of $20 \mathrm{~V}$, which is due to the low electrical conductivity of the anolyte. Further, it decreased due to an increase in the concentration of salts in the anode region, as in the previous case, to $10 \mathrm{~V}$ and at the end increased to $25 \mathrm{~V}$, which is explained by a decrease in the level of mineralization of the working solution and an increase in the resistance of the catholyte. The recovery of chlorides from the $\mathrm{NaCl}$ solution was also quite high.
With an increase in the current strength to $0.5 \mathrm{~A}$, the intensity of the desalination of the sodium chloride solution increased significantly. Thus, at 5 hours, the concentration of chlorides in the working chamber decreased to $2.25 \mathrm{mg}$-eq $/ \mathrm{dm}^{3}$ with an increase in alkalinity in the catholyte to $312 \mathrm{mg}$-eq $/ \mathrm{dm}^{3}$ and with an increase in the concentration of iron in the anolyte to $263 \mathrm{mg}$-eq $/ \mathrm{dm}^{3}$ (Fig. 7).

This led to an increase in the degree of removal of chlorides from the working solution up to $99.2 \%$. However, the current efficiency of alkali and ferric chloride did not increase (Fig. 8).

Obviously, this significantly increased the energy consumption directly for the electrolysis of 


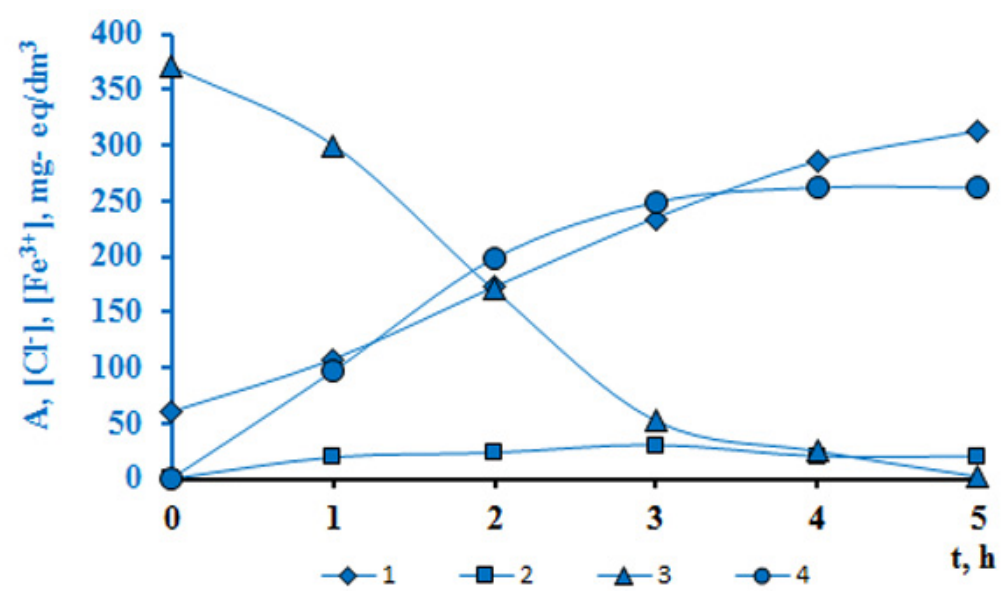

Fig. 7. Change in alkalinity in the cathode region (1) and working chamber (2), chloride concentration in the working chamber (3), iron concentration (4) in the anode chamber during electrolysis of $\mathrm{NaCl}$ solution

$\left([\mathrm{NaCl}]=370 \mathrm{mg}\right.$-eq $\left./ \mathrm{dm}^{3}\right)$ in a three-chamber electrolyzer $\left(\mathrm{V}_{\mathrm{k}}=75 \mathrm{~cm}^{3}, \mathrm{I}=0.2 \mathrm{~A}, \mathrm{j}=4.17 \mathrm{~A} / \mathrm{dm}^{3}\right)$

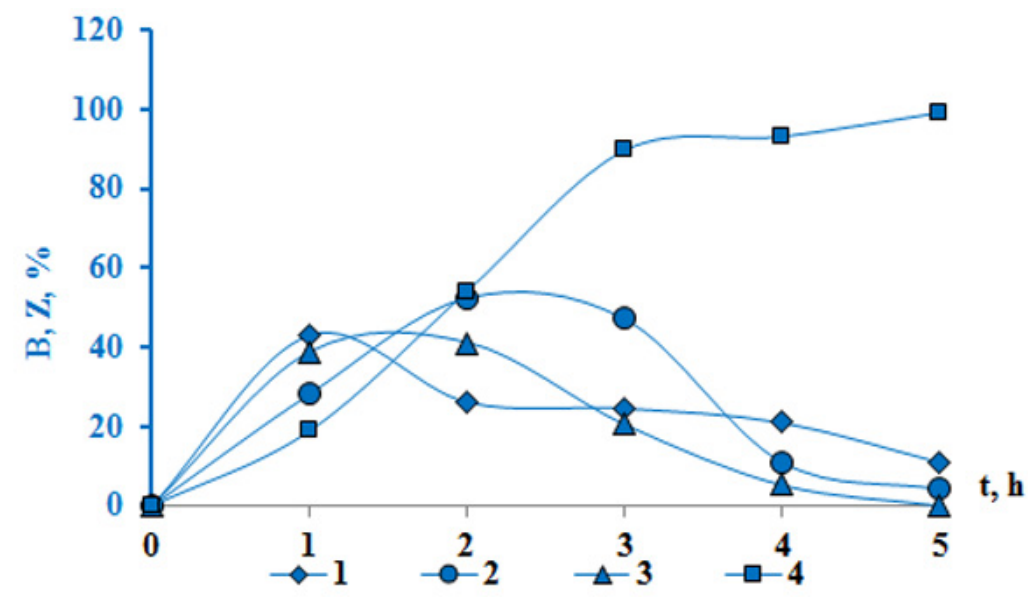

Fig. 8. Change in the current efficiency over the meadow in the cathode region (1), for iron in the anode region (2), for the diffusion of chlorides from the working chamber (3) and the degree of removal of chlorides (4) with the time of electrolysis of the $\mathrm{NaCl}$ solution $\left([\mathrm{NaCl}]=370 \mathrm{mg}\right.$-eq $\left./ \mathrm{dm}^{3}\right)$ in a three-chamber electrolyzer $\left(V_{k}=75 \mathrm{~cm}^{3}, I=0.2 \mathrm{~A}, \mathrm{j}=4.17 \mathrm{~A} / \mathrm{dm}^{3}\right)$

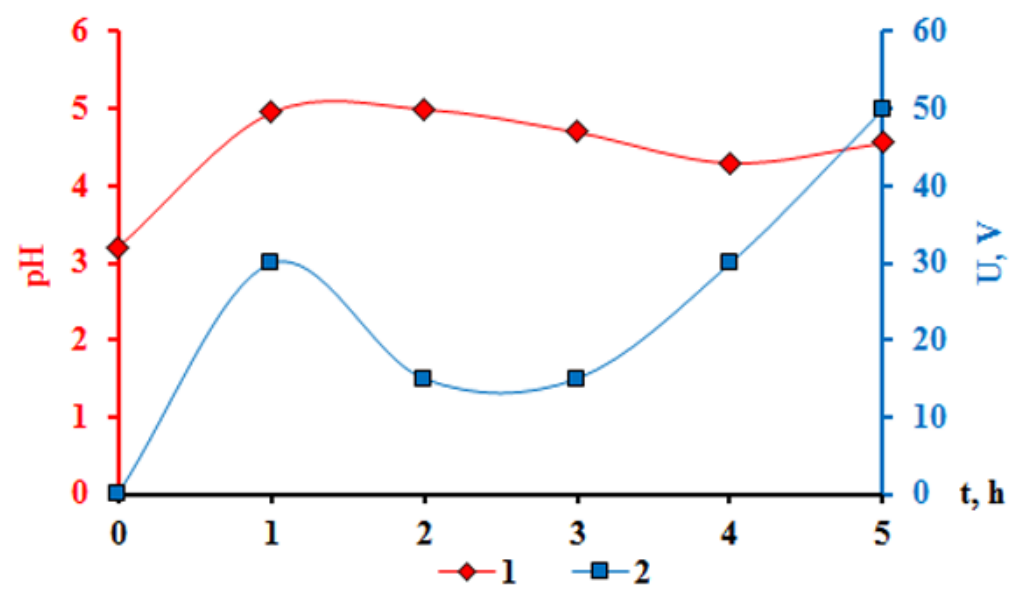

Fig. 9. Change of $\mathrm{pH}$ (1) in the anodic region, voltage (2) with the time of electrolysis of $\mathrm{NaCl}$ solution $\left([\mathrm{NaCl}]=370 \mathrm{mg}\right.$-eq $\left./ \mathrm{dm}^{3}\right)$ in a three-chamber electrolyzer $\left(\mathrm{V}_{\mathrm{k}}=75 \mathrm{~cm}^{3}, \mathrm{I}=0.2 \mathrm{~A}, \mathrm{j}=4.17 \mathrm{~A} / \mathrm{dm}^{3}\right)$ 
water and heating the solution. In this case, the voltage first decreased from $30 \mathrm{~V}$ to $15 \mathrm{~V}$, and as the working solution became desalted, it increased to $30 \mathrm{~V}$, and then to $50 \mathrm{~V}$ (Fig. 9).

Under these process conditions, the $\mathrm{pH}$ of the solution in the anolyte varied within 3.2-5.0.

\section{CONCLUSIONS}

It was shown that during electrolysis of a sodium chloride solution with a concentration of $370 \mathrm{mg}-\mathrm{eq} / \mathrm{dm}^{3}$ at a current of $0.2 \mathrm{~A}$ in a threechamber electrolyzer with an iron anode, an iron chloride solution is formed in the anolyte at $\mathrm{pH}<4$.9. The rate of concentration of $\mathrm{NaOH}$ to catholyte and $\mathrm{FeCl}_{3}$ to anolyte increases along with the current density

In order to increase the concentration of iron (III) chloride in the anolyte at relatively low concentrations of sodium chloride solution, it is advisable to gradually renew the desalted solutions in the working chamber.

\section{REFERENCES}

1. Adeniyi A., Maree J., Mbaya R., Popoola A., Mtombeni T., Zvinowanda C. 2014. HybridICE® Filter: Ice Separation in Freeze Desalination of Mine Waste Water. Water Science and Technology, 69 (9), 1820-1827.

2. Akhter M., Habib G., and Qamar S. 2018. Application of Electrodialysis in Waste Water Treatment and Impact of Fouling on Process Performance. Journal of Membrane oJ Science \& Technology, 8(2), 1-8.

3. Bazrafshan E., Ownagh K., Mahvi A. 2012. Application of electrocoagulation process using iron and aluminum electrodes for fluoride removal from aqueous environment. E-Journal of Chemistry, 9(4), 2297-2308.

4. Bennamoun L., Arlabosse P., Leonard A. 2013. Review on fundamental aspect of application of drying process to wastewater sludge. Renewable and Sustainable Energy Reviews, 28, 29-43.

5. Chafi M., Gourich B., Essadki A., Vial C., Fabregat A. 2011. Comparison of electrocoagulation using iron and aluminium electrodes with chemical coagulation for the removal of a highly soluble acid dye. Desalination, 281, 285-292.

6. Epsztein R., Nir O., Lahav O., Green M. 2015. Selective nitrate removal from groundwater using a hybrid nanofiltration-reverse osmosis filtration scheme. Chemical Engineering Journal, 279, 372-378.

7. Ferry J., Widyolar B., Jiang L., Winston R. 2020.
Solar thermal wastewater evaporation for brine management and low pressure steam using the XCPC. Applied Energy, 265.

8. Gomelya M., Hrabitchenko V., Trokhymenko A., Shabliy T. 2016. Research into ion exchange softening of highly mineralized waters. Easten-Europen journal of Enterprise Technologies, 4/10 (82), 4-9.

9. Gomelya M., Shabliy T., Radovenchyk I., Overchenko T., Halysh V. 2019. Estimation of the efficiency of ammonia oxidation in anolyte of two-chamber electrolyzer. Journal of Ecological Engineerig, 20, 5, 121-129.

10. Gomelya M., Trohymenko A., Hlushko O., Shabliy T. 2018. Electroextraction of heavy metals from wastewater for the protection of natural water bodies pollution. Eastern-European Journal of enterprise technologies, 1/10 (91), 55-61.

11. Goncharuk V., Osipenko V., Balakina M., Kucheruk D. 2013. Water purification of nitrates by lowpressure reverse osmosis method. Journal of Water Chemistry and Technology, 35, 71-75.

12. Htira T., Cogné C., Gagniere E., Mangin D. 2018. Experimental study of industrial wastewater treatment by freezing. Journal of Water Process Engineering, 23, 292-298.

13. Lin Chen, Huiyao Wang, Sarada Kuravi, Krishna Kota, Young Ho Park, Pei Xu. 2020. Low-cost and reusable carbon black based solar evaporator for effective water desalination. Desalination, 483.

14. Makarenko I., Hlushko O., Rycuhin V., Tereschenko O. 2013. Application of subacid cationites for water conditioning in baromembrane demineralization. Easten-Europen journal of Enterprise Technologies, 3/6 (63), 48-52.

15. Naidu L. D., Saravanan S., Chidambaram M., Goel M., Das A., Sarat J., Babu C. 2015. Nanofiltration in Transforming Surface Water into Healthy Water: Comparison with Reverse Osmosis. Journal of Chemistry, 2015, 1-6.

16. Shabliy T., Gomelya M., Panov Ye. 2010. Electrochemical treatment of spent solutions formed during the regeneration of cation-exchange resins. Ecology and industry, 2, 33-38. (In Ukrainian).

17. Shata M., Riffat S. 2014. Water desalination technologies utilizing conventional and renewable energy sources. International Journal of Low-Carbon Technologies, 9, 1-19.

18. Trus I., Gomelya M., Radovenchyk I. 2013. Influence of preliminary mechanical water purification on the efficiency of reverse osmosis water desalination. Visnik of the Volodymyr Dahl East Ukrainian National University, 9(198) p.2, 197-202. (In Ukrainian).

19. Wenyi Deng, Yaxin Su, Weichao Yu. 2013. Theoretical Calculation of Heat Transfer Coefficient When Sludge Drying in a Nara-Type Paddle Dryer Using Different Heat Carriers. Procedia Environmental Sciences, 18, 709-715. 